\title{
Finite Element Analysis of Needle Insertion Angle in Insulin Therapy
}

\author{
S. M. Amin 1 , M. H. Ramlee ${ }^{1 *}$, H. F. Mohd Latip ${ }^{2}$, H. S. Gan ${ }^{3}$ and \\ M. R. Abdul Kadir ${ }^{2}$ \\ ${ }^{1}$ Medical Devices and Technology Centre (MEDITEC), Institute for Human Centered \\ Engineering (i-Humen), School of Biomedical Engineering and Health Sciences, \\ Faculty of Engineering, Universiti Teknologi Malaysia, 81310 UTM Johor Bahru, \\ Johor, Malaysia \\ ${ }^{2}$ Sports Innovation and Technology Centre (SITC), Institute for Human Centered \\ Engineering (i-Humen), Universiti Teknologi Malaysia, 81310 UTM Johor Bahru, \\ Johor, Malaysia \\ ${ }^{3}$ Universiti Kuala Lumpur, British Malaysian Institute, Jalan Sungai Pusu, 53100 \\ Gombak, Selangor, Malaysia \\ *Email: muhammad.hanif.ramlee@ biomedical.utm.my \\ Phone: +60126754717
}

\begin{abstract}
Millions in the world suffering diabetes mellitus depends on insulin therapy to control their blood glucose level daily. However, the painful daily injections they need to take could lead to other complications if it is not done correctly. To date, it is suggested by many researchers and medical doctors that the needles should be inserted at any angles of $90^{\circ}$ or $45^{\circ}$. Nevertheless, this recommendation has not been supported by clinical or biomechanical evaluation. Hence, this study evaluates the needle insertion for insulin therapy to find the favourable angles in order to reduce injury and pain onto the skin. Finite element analysis was done by simulating the injection of three-dimensional (3D) needle model into a 3D skin model. The insertions were simulated at two different angles, which are $45^{\circ}$ and $90^{\circ}$ with two different lengths of needles; $4 \mathrm{~mm}$ and $6 \mathrm{~mm}$. This study concluded the favourable angle for $4 \mathrm{~mm}$ needle to be $90^{\circ}$ while $6 \mathrm{~mm}$ needle was best to be inserted at $45^{\circ}$ as these angles exerted the least maximum stress and strain onto the skin.
\end{abstract}

Keywords: Diabetes mellitus; insulin therapy; insulin needle; favourable angle; finite element.

\section{INTRODUCTION}

There are approximately millions suffering from diabetes mellitus across the world [1,2]. The numbers are increasing tremendously yearly and this issue raises great concern. Diabetes sufferers need insulin to stabilize their blood sugar level daily. For this, they require daily injections depending on the condition, some would need up to 4 injections a day. This invasive insulin delivery technique is the most common technique among diabetes patients as it is the first technique that has been created in history. However, this technique causes injuries to the skin and causes trauma to patients due to pain experienced [3]. Even though it causes pain, currently it is still the most dependable method of delivering insulin when compared to the non-invasive method [4]. This is because the non-invasive method is still new and its products are still not widely available in the 
market. Besides that, the correct injection technique is crucial in insulin therapy because it could cause life-threatening complications to the patient such as intramuscular injection and hypoglycemia. Intramuscular injection happens when insulin needle is inserted deeper than the subcutaneous layer. When insulin is delivered to layer deeper than this layer, insulin absorption is distorted $[4,5]$.

Distortion of insulin absorption further raise the higher risk for patients to experience unpredictable fluctuation of blood sugar level and may experience hypoglycemia, a condition where there is excessive insulin delivered in the body causing blood sugar level of the patient to be extremely low [6]. Hence, to minimise pain and reduce injury to the skin, a correct needle insertion technique must be practised by patients to prevent further complications and at the same time to provide a better experience in insulin therapy. The angle of insulin needle insertion used by the patient is important in insulin therapy injection technique as the favourable angle of needle insertion minimise injury caused to skin and further prevent the over-penetration of the needle onto the skin. As far as the authors are concerned, the recommended angles are $45^{\circ}$ and $90^{\circ}$ [5, 7-9]. However, these recommendations are not supported by any biomechanical or clinical evaluation.

Some studies have been conducted to evaluate needle insertion for femoral vein catheterization in different angles, however, the evaluation of needle used in insulin therapy is still limited in the literature [10]. Furthermore, the research also stresses on different angles of needle insertion cause a different level of injury and pain to the skin. This is due to the use of the angle of needle insertion caused different forces such as stress and strain to the skin. Pain receptors [11] in the skin is highly affected by the changes of strain in skin and stress applied to it. Higher forces of stress and strain stimulate greater pain receptors in the skin causing patients to experience greater pain $[11,12]$. Thus, the favourable angle of needle insertion for insulin therapy need to be evaluated to recommend the best angle for patients to minimise injury and pain while reducing risks of complications [12].

The main objective of this study is to evaluate the favourable angle of needle insertion in insulin therapy by evaluating the maximum stress and strain of skin and needle model via finite element method [10]. Finite element method is a numerical method that can simulate the behaviour of human as well as other models [13-16]. The study contributes to the angles of needle insertion used in insulin therapy biomechanically. The favourable angle of needle insertion would have the least stress and strain which minimises injury and pain experienced by the patients. Though there are various lengths of insulin needles ranging from 4 to $12.7 \mathrm{~mm}$, the shorter needle was stated in some research studies to be most efficient in delivering insulin by minimizing damage to skin tissues $[17,18]$. The injection technique questionnaire (ITQ) conducted in 2009 and 2017 reported the shift among insulin therapy patients to use shorter needles [19]. Hence this study utilised the shorter length of insulin needle as it is the most relevant needles used by patients. Skin thickness was reported in a study to be consistent in thickness in the range of 2 to $2.5 \mathrm{~mm}$ when ITQ was conducted among respondents with various age, race and BMI [19]. However, skin thickness differs when a different anatomical region is measured, for instance, the abdomen was observed to have the thickest subcutaneous layer from other regions [20]. The abdomen was the most common injection site used among insulin therapy patients [21,22]. Apart from that, the coefficient of friction of skin also varies with different layers of skin due to the composition of structures in the different layers of the skin [23]. The 5-bevel tip needle design has the highest occurrence in research studies reviewed as it suggested to reduce the penetration 
force of the needle during insertion [24]. Through this study, it is hoped that the findings can help the patients by choosing a suitable angle in minimising the complications.

\section{METHODOLOGY}

To evaluate the maximum stress and strain of the skin and needle via the finite element method, the models must first be developed. The software that had been used in this study for developing a 3D model of skin are Mimics and 3-Matic (Materialise, Leuven, Belgium). It was used to model the skin while the development of needle had been done using Solidworks (Dassault Systèmes®, Vélizy-Villacoublay, France) and 3-Matic software. The simulation of the needle model insertion onto the skin model at different angles was conducted through finite element method that had been done using Marc. Mentat (MSC.Software, Santa Ana, CA) software.

\section{Skin Modelling}

Skin model was reconstructed from Computed Tomography (CT) images dataset of a normal healthy person that obtained from a previous study [25]. The ethical approval for this dataset was obtained from Hospital Tengku Ampuan Afzan, Kuantan, Pahang, Malaysia. In order to reconstruct the skin model, the CT images in DICOM format were imported to Mimics software where the thresholding value (Hounsfield unit) of the skin of abdomen region was ranging from -718 to -177 . A segment of skin was developed through a masking process in Mimics software where the dimension of $3 \times 3 \mathrm{~mm}$ was selected to simulate the needle insertion. The segmented skin was then reconstructed below the original layer with the average length of epidermis layer abdomen region among the Asian population which is $2.47 \pm 0.42 \mathrm{~mm}$ [20]. Therefore, the thickness of the skin was set to $2.5 \mathrm{~mm}$. Meshing process had been done manually for the connection of the two layers which were the skin and the epidermis layer [26]. When these were connected, a remeshing process was conducted to complete the 3D model for FEA analysis. Figure 1 shows the completed 3D model of the skin.

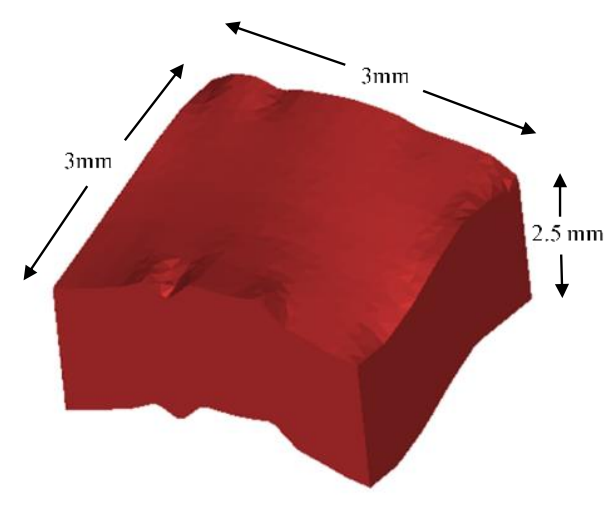

Figure 1. A complete model of human skin.

\section{3-D Modelling of Needle Model}

The needle was modelled using Solidworks software where firstly a two-dimensional (2D) sketch of a circle with a diameter of $0.23 \mathrm{~mm}$ was drawn. Then, it was extruded to $4 \mathrm{~mm}$ and $6 \mathrm{~mm}$ length to form a three-dimensional (3D) cylinder of the needles. These 
two lengths of the needle were used in this study because it is the shortest length of an insulin needle. It should be noted that shorter lengths of insulin needles were proven to minimise penetration force onto the skin during needle insertion [27]. The inner diameter of $0.105 \mathrm{~mm}$ was set to make the needle hole. Furthermore, the tip of the needle was cut specifically to mimic the 5-bevel needle tip design. This tip design has 5 angles comprising a pair of the middle bevel, a pair of tip bevel, and a primary bevel as depicted in Figure 2 below. The needle was then exported and saved as an STL file.

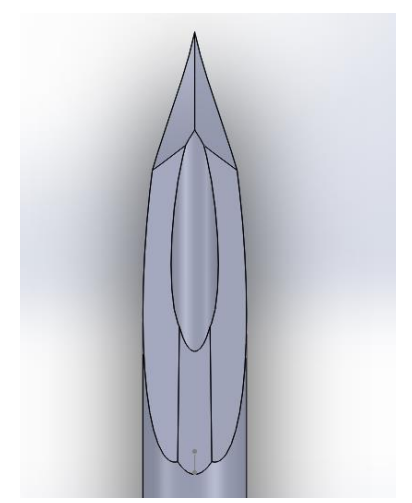

(a)

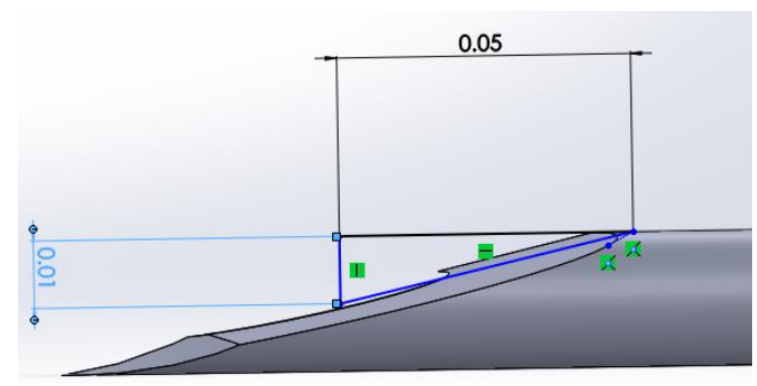

(b)

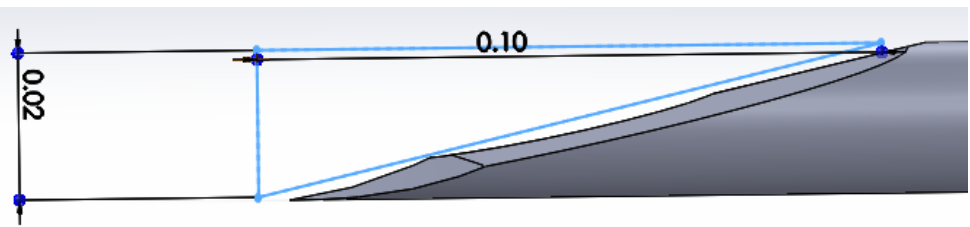

(c)

(All unit in $\mathrm{mm}$ )

Figure 2. The design of 5-bevel tip needle in (a) top view, (b) and (c) side view with respective dimensions. All unit are in $\mathrm{mm}$.

\section{Fixation of Needle into Skin Model}

The needle was assumed to be in 'tie' and its tip to be fully inserted into skin model according to Halabian et al. [10] as this would minimise errors during simulation of finite element analysis. In Mimics software, the needle and skin models were loaded as STL file. Then the needles were manipulated at two different angles which are $45^{\circ}$ and $90^{\circ}$. These two angles were chosen as it is the most relevant angles to be used by patients. Figure 3 below shows the fixation of the needle onto the skin at $45^{\circ}$ and $90^{\circ}$. Moreover, the positioned skin and needle model was then loaded in 3-Matics software where both models meshed for the mesh size of 0.12[28] and the touching interface of the skin and needle was meshed using non-manifold assembly. The models were then split and exported as two models in Patran format. Both needles size of 4 and $6 \mathrm{~mm}$ were positioned at two different angles, $45^{\circ}$ and $90^{\circ}$. At the final stage of modelling, there were 4 models that have be analysed via finite element method. 


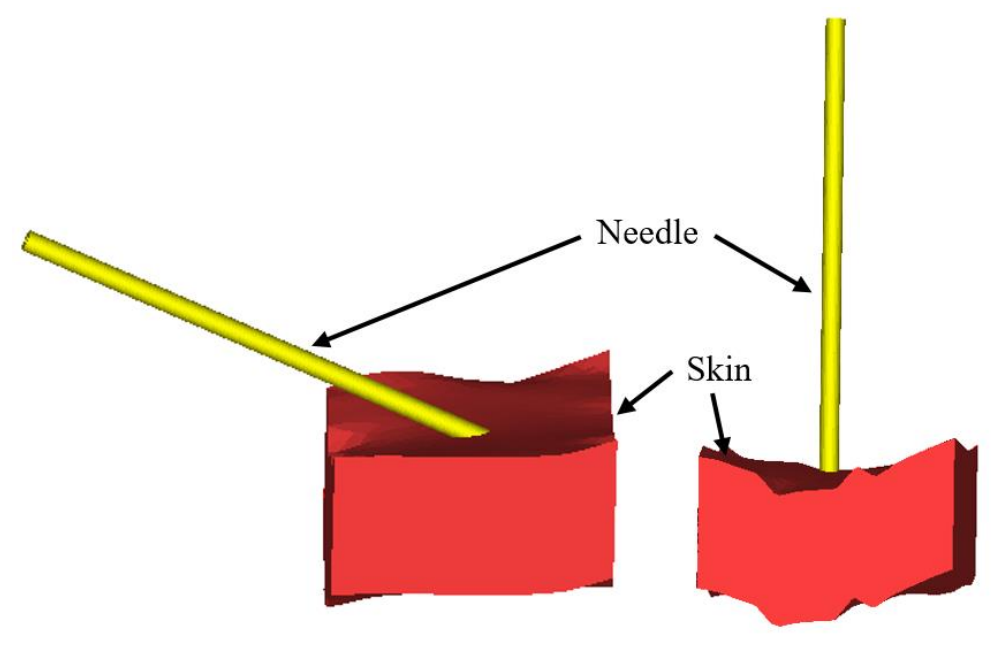

(a) $45^{\circ}$

(b) $90^{\circ}$

Figure 3. Fixation of $6 \mathrm{~mm}$ needles at different angles.

\section{Finite Element Analysis}

Patran files of skin and needle models were loaded in Marc.Mentat (MSC.Software, Santa Ana, CA) software. Different material properties of the models were described as in Table 1. To simulate the needle insertion onto skin, a load was applied to the needle and the distal skin surfaces were fixed in all degree of freedom as shown in Figure 4.

Table 1. Material properties of needle and skin model.

\begin{tabular}{|c|c|c|}
\hline & Needle & Skin \\
\hline $\begin{array}{l}\text { Type of } \\
\text { material }\end{array}$ & Isotropic & Isotropic \\
\hline $\begin{array}{l}\text { Young } \\
\text { modulus } \\
(\mathrm{MPa})\end{array}$ & $198600[29]$ & $2.1[10]$ \\
\hline $\begin{array}{l}\text { Poisson's } \\
\text { ratio }\end{array}$ & $0.263[29]$ & $0.3[10]$ \\
\hline $\begin{array}{l}\text { Friction } \\
\text { coefficient }(\mu)\end{array}$ & $0.5[30]$ & $0.12[31]$ \\
\hline $\begin{array}{l}\text { Boundary } \\
\text { condition }\end{array}$ & $\begin{array}{l}\text { A } 1 \mathrm{~N} \text { force was applied as in Figure } 4 \\
\text { by using face load exerted on the free } \\
\text { end part of the needle }\end{array}$ & $\begin{array}{l}\text { Bottom of the skin was set to } \\
\text { fixed displacement in all } \\
\text { directions. }\end{array}$ \\
\hline
\end{tabular}




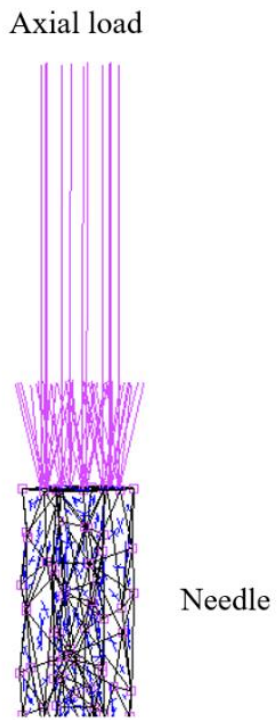

Figure 4. Force applied at the proximal needle. This is applicable at both $45^{\circ}$ and $90^{\circ}$ of needle insertion.

\section{RESULTS AND DISCUSSION}

Figure 5 and 6 shows the maximum stress and strain of the skin models during insertion at a $45^{\circ}$ angle while Figure 7 shows the contour plot of the stress of needle models. As comparing both sizes of the needle, it shown that the $6 \mathrm{~mm}$ length experience high stress $(4.559 \mathrm{MPa})$ at the skin than the $4 \mathrm{~mm}$ size (4.248 MPa). Even though there were some differences in terms of stress distribution, however the different is small where the percentage change is $7.32 \%$. A similar pattern has been demonstrated in the results of strain where the higher strain (1.355) observed for model $6 \mathrm{~mm}$ length. While for model $4 \mathrm{~mm}$ length, the strain is 1.143 in which $15.65 \%$ different with the highest one. For the stress at the needle models, size of $6 \mathrm{~mm}$ demonstrated the higher value $(122.5 \mathrm{MPa})$ as compared with $4 \mathrm{~mm}$ size $(96.4 \mathrm{MPa})$. Nevertheless, these values are not exceeding the ultimate strength of that material of stainless steel (800-900 MPa). The highest stress that obtained from $6 \mathrm{~mm}$ needle size is may due to the bending moment that occurred when the axial load was applied perpendicular to the top surface of the needle. The longest insulin tends to introduce higher bending moment and therefore the skin needs to sustain the load more. This situation leads to increasing stress distribution at the skin surface. 
von Mises stress (MPa)

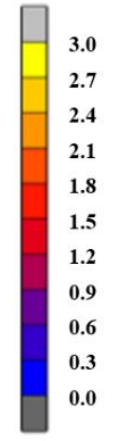

a) $4 \mathrm{~mm}$ needle

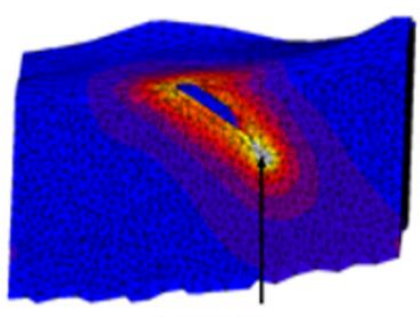

4.248 MPa b) $6 \mathrm{~mm}$ needle

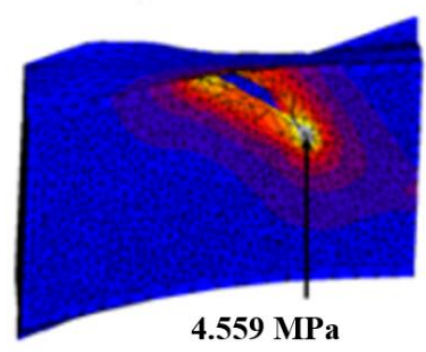

Figure 5. Contour plot of the stress of skin model at $45^{\circ}$ angle needle insertion.

\section{Equivalent total \\ strain}

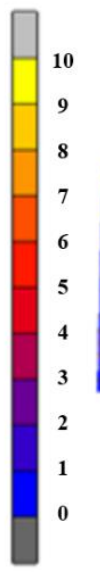

a) $4 \mathrm{~mm}$ needle

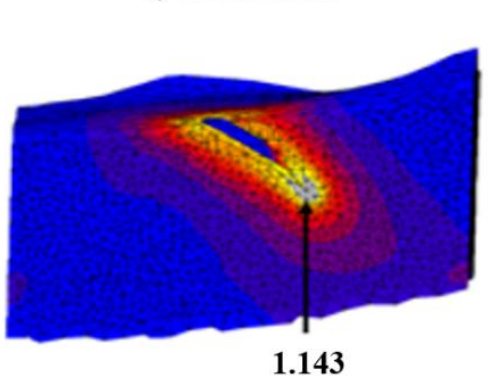

b) $6 \mathrm{~mm}$ needle

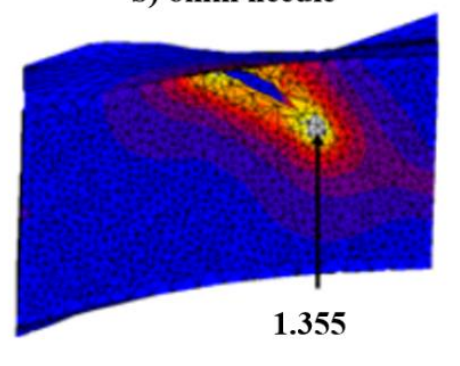

Figure 6. Contour plot of the strain of skin model at $45^{\circ}$ angle needle insertion.

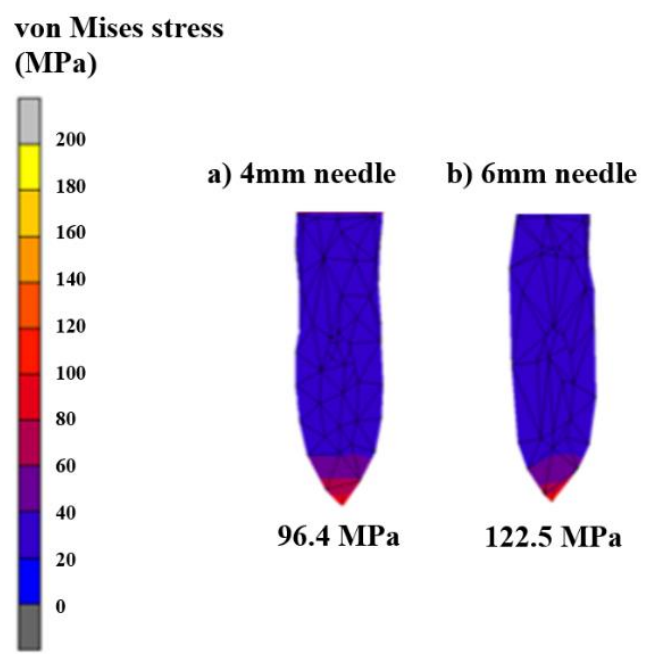

Figure 7. Contour plot of the stress of needle model at $45^{\circ}$ angle needle insertion 
Results for $90^{\circ}$ angle insertion are illustrated in Figure 8 until 10. Figure 8 shows the contour plot of stress of skin model. The $6 \mathrm{~mm}$ length contributed the higher stress (4.971 MPa) as compared with the size of $4 \mathrm{~mm}$ (3.969 MPa). This results showed $20.16 \%$ different value. Figure 9 shows the contour plot of strain of skin model where the larger value was found at the model of $6 \mathrm{~mm}$ length (1.428) while the model of $4 \mathrm{~mm}$ showing 1.088 value in strain. As for the needle model in Figure 10, it shows that the size of $6 \mathrm{~mm}$ length experienced higher stress $(239.3 \mathrm{MPa})$ where at least $60 \%$ difference to that of model $4 \mathrm{~mm}$ length. This results indicated that the use of $6 \mathrm{~mm}$ length for $90^{\circ}$ insertion method should be taken seriously to avoid any complications to the patients. Although the value is still not exceeding the ultimate strength of that material, however, the findings showed this method of insertion is the worst.
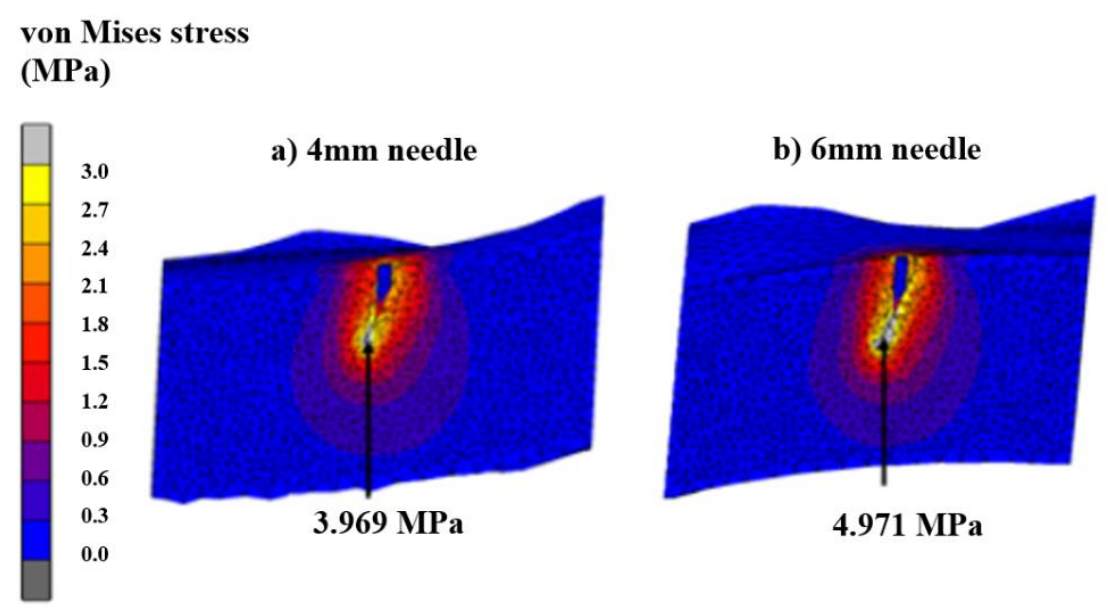

Figure 8. Contour plot of the stress of skin model at $90^{\circ}$ angle needle insertion

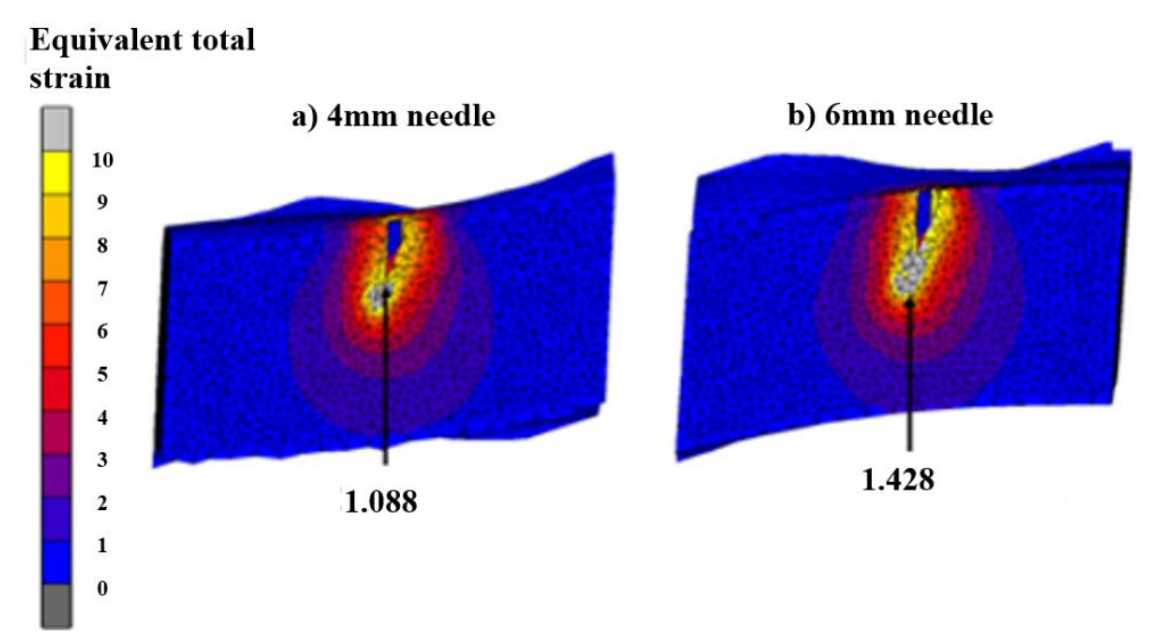

Figure 9. Contour plot of strain of skin model at $90^{\circ}$ angle needle insertion 


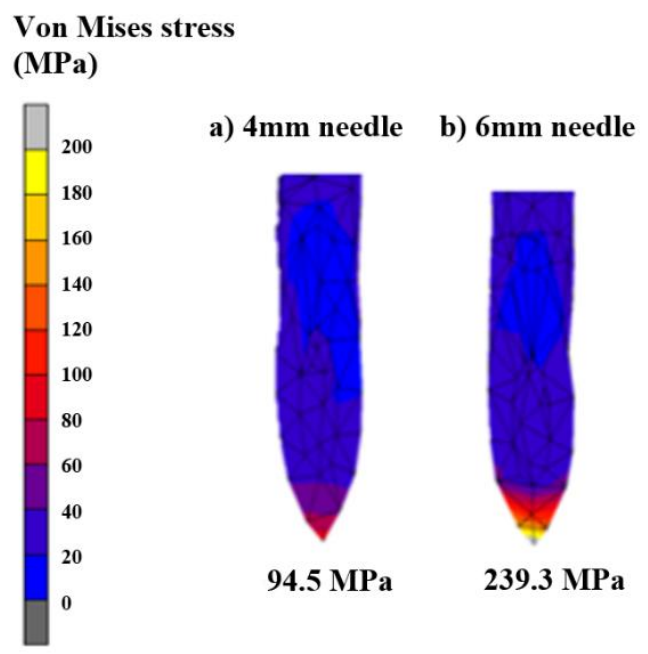

Figure 10. Contour plot of the stress of needle model at $45^{\circ}$ angle needle insertion

The stress distribution in the skin models illustrated that the insertion method at an angle of $45^{\circ}$ can cause an irregular and approximately greater as compared to insertion method at an angle of $90^{\circ}$. Greater stress distribution may cause more pain receptors to be stimulated as there was greater area was affected by the stress. The different favourable angles indicated by the analysis of the skin model shows that $4 \mathrm{~mm}$ needle exerts a smaller force when it is inserted perpendicularly while longer needle exerts a smaller force when it is inserted at an angle of $45^{\circ}$. This could imply that there may be the threshold length of needle that can reduce the force exerted onto the skin when it is inserted at an angle as it splits the force. Hence, this gives a different perspective on the threshold length of needle that could reduce the force. The values of stress and strain could also be supported in the analysis of the needle model. Lowest stress and strain indicates the favourable angle of needle insertion. The favourable angle of needle insertion differs when the length of needle changes where $4 \mathrm{~mm}$ needle was the best length to be inserted at $90^{\circ}$ and $6 \mathrm{~mm}$ needle should be inserted at $45^{\circ}$ as inserting at these angles exerts the lowest stress and strain onto skin tissue. Hence, this would minimise injury and pain in the skin.

Though the finite element analysis in this study can provide numerical predictions on the human body, however, there are some limitations and assumptions that have been applied throughout the simulation procedures. Firstly, the development of skin model was reconstructed from CT images dataset. As far as the authors aware, the use of CT images is suitable for screening hard tissue such as cortical and cancellous bone. For the development of soft tissue model, i.e. skin and muscle, it should be noted that the Magnetic Resonance Imaging (MRI) dataset is more suitable to be used. Secondly, we did not manage to conduct convergence study to determine favourable value of mesh size. This is due to limited resources of Random Access Memory (RAM) in the power computer in our laboratory. Therefore, the size of $0.12 \mathrm{~mm}$ was used in this study is based on a previous published article by Kim et. al [28]. Next limitation is that the surface area of skin was set $3 \times 3 \mathrm{~mm}$ for needle insertion with $2.5 \mathrm{~mm}$ thickness that refer for the geometrical condition of the Asian population. The results obtained here is only consider this region as the other region may produce different von Mises stress and strain. The other limitation of this study is the region of skin where the abdomen region was selected. This region was used is due to the fact that the needle insertion was at the abdomen region. Therefore, these findings are conclusive to this region of interest. In addition, the behavior of skin was assumed to be in isotropic and homogenous material properties. To be noted, 
the skin is like to behave in hyper-elastic properties. In this study, the assumption of skin in isotropic and homogeneous properties was made due to the fact that there are no specific material properties found in the literature and due to limited resources of memory in the computer to simulate a complex model of hyper-elastic material. Therefore, future study should be done by considering the real nature of skin properties.

\section{CONCLUSION}

Insulin needle insertion techniques is one of the element that need to be considered for preventing skin injury to patients. The current study was conducted to analyse the different angles of insulin needle through a finite element method. From the findings, it can be concluded that the favourable angle for insulin therapy to be $6 \mathrm{~mm}$ needle size as this illustrated the lowest stress and strain onto the skin. It is found that the value of stress (3.969 $\mathrm{MPa}$ ) at the skin for $90^{\circ}$ insertion technique is lower than other method with $45^{\circ}$ $(4.248 \mathrm{MPa})$ with similar diameter of needle $(4 \mathrm{~mm})$. Therefore, it is hope that these findings will give an overview to the Diabetes patients to apply correct insertion technique in preventing any complications during the treatment.

\section{ACKNOWLEDGEMENT}

The authors would like to thank all students and staffs from the School of Biomedical Engineering and Health Sciences, Faculty of Engineering, Universiti Teknologi Malaysia for their endless supports to finish this research project. Special thanks to the Medical Devices and Technology Centre (MEDITEC) and Institute for Human Centered Engineering (i-Humen) for providing special facilities and equipment such as power computer, data analysis system and simulation software. This research was supported by the university grant under Tier 1 scheme (Q.J130000.2745.20H26 and Q.J130000.2545.20H20) and PRGS-ICC scheme (R.J130000.7751.4J358).

\section{REFERENCES}

[1] Zimmet P, Alberti KGMM, Shaw J. Global and societal implications of the diabetes epidemic. Nature. 2001;414:782.

[2] Praestmark KA Stallknecht B, Jensen ML, Sparre T, Madsen NB, Kildegaard J. Injection technique and pen needle design affect leakage from skin after subcutaneous injections. Journal of diabetes science and technology. 2016;10:914-22.

[3] Diamond SA, Matok I. Pharmacists' Anticipated Pain Compared to Experienced Pain Associated with Insulin Pen Injection and Fingertip Lancing. Canadian Journal of Diabetes. 2011;35:282-6.

[4] Praestmark KA Jensen ML, Madsen NB, Kildegaard J, Stallknecht BM. Pen needle design influences ease of insertion, pain and skin trauma in subjects with type 2 diabetes. BMJ Open Diabetes Research \& Care. 2016;4:e000266.

[5] Frid AH, Kreugel G, Grassi G, Halimi S, Hicks D, Hirsch LJ, et al. New Insulin Delivery Recommendations. Mayo Clin Proc. 2016;91:1231-55.

[6] Kreider KE, Padilla BI, Pereira K. Hypoglycemia in Diabetes: Challenges and Opportunities in Care. The Journal for Nurse Practitioners. 2017;13:228-34. 
[7] Aronson R, Gibney MA, Oza K, Berube J, Kassler-Taub K, Hirsch L. Insulin pen needles: effects of extra-thin wall needle technology on preference, confidence, and other patient ratings. Clin Ther. 2013;35:923-33 e4.

[8] Frid AH, Hirsch LJ, Menchior AR, Morel DR, Strauss KW. Worldwide Injection Technique Questionnaire Study: Injecting Complications and the Role of the Professional. Mayo Clin Proc. 2016;91:1224-30.

[9] Hansen B, Matytsina I. Insulin administration: selecting the appropriate needle and individualizing the injection technique. Expert Opinion on Drug Delivery. 2011;8:1395-406.

[10] Halabian M, Beigzadeh B, Karimi A, Shirazi HA, Shaali MH. A combination of experimental and finite element analyses of needle-tissue interaction to compute the stresses and deformations during injection at different angles. J Clin Monit Comput. 2016;30:965-75.

[11] Egekvist H, Bjerring P, Arendt-Nielsen L. Pain and mechanical injury of human skin following needle insertions. European Journal of Pain. 2012;3:41-9.

[12] Praestmark KA JC, Stallknecht B, Madsen NB, Kildegaard J. Skin blood perfusion and cellular response to insertion of insulin pen needles with different diameters. Journal of diabetes science and technology. 2014;8:752-9.

[13] Zulkifli A, Ariffin A, Rahman M. Probabilistic finite element analysis of vertebrae of the lumbar spine under hyperextension loading. International Journal of Automotive and Mechanical Engineering. 2011;3:236-64.

[14] Sedighi M, Dardashti B. Finite element analysis of heat transfer in multi-layer cooking pots with emphasis on layer number. International Journal of Automotive and Mechanical Engineering. 2015;11:2253-61.

[15] Ramlee MH, Beng GK, Bajuri N, Abdul Kadir MR. Finite element analysis of the wrist in stroke patients: the effects of hand grip. Medical \& Biological Engineering \& Computing. 2017.

[16] Ramlee MH, Abd Wahab AH, Abd Wahab A, Mohd Latip HF, Daud SA, Abdul Kadir MR. The effect of stress distribution and diplacement of open subtalar dislocation in using titatium alloy and stainless steel mitkovic external fixator- a finite element analysis. Malaysian Journal of Fundamental and Applied Sciences. 2017:477-82.

[17] Li CG, Ma Y, Huh I, Lahiji SF, Lee S-G, Jung H. A Novel Ultrafine Needle (UN) for Innocuous and Efficient Subcutaneous Insulin Delivery. Advanced Functional Materials. 2017;27.

[18] Cheung K, Han T, Das DG. Effect of force of microneedle insertion on the permeability of insulin in skin. Journal of diabetes science and technology. 2014;8:444-52.

[19] Frid AH, Hirsch LJ, Menchior AR, Morel DR, Strauss KW. Worldwide Injection Technique Questionnaire Study: Population Parameters and Injection Practices. Mayo Clin Proc. 2016;91:1212-23.

[20] Wang W, Guo X, Shen G, Bai G, Wei Z, Liu J, et al. Skin and subcutaneous tissue thickness at insulin injection sites in Chinese diabetes patients: Clinical implications. Diabetes Metab. 2016;42:374-7.

[21] Grassi G, Scuntero P, Trepiccioni R, Marubbi F, Strauss K. Optimizing insulin injection technique and its effect on blood glucose control. J Clin Transl Endocrinol. 2014;1:145-50. 
[22] $\mathrm{CH}$ SV, Chen CT. Dissolving microneedle patches for transdermal insulin delivery in diabetic mice: potential for clinical applications. Materials. 2018;11:1625.

[23] Geerligs M. Skin layer mechanics [Phd Thesis 1 (Research TU/e / Graduation TU/e)]: Technische Universiteit Eindhoven 2010.

[24] Hirsch L, Gibney M, Berube J, Manocchio J. Impact of a Modified Needle Tip Geometry on Penetration Force as well as Acceptability, Preference, and Perceived Pain in Subjects with Diabetes. Journal of Diabetes Science and Technology. 2012;6:328-35.

[25] Ramlee MH SM, Garcia-Nieto E, Penaranda DA, Felip AR, Abdul Kadir MR. Biomechanical features of six design of the delta external fixator for treating Pilon fracture: a finite element study. Medical \& Biological Engineering \& Computing. 2018;56:1925-38.

[26] Ramlee MH, Kadir MRA, Murali MR, Kamarul T. Biomechanical evaluation of two commonly used external fixators in the treatment of open subtalar dislocationA finite element analysis. Medical Engineering \& Physics. 2014; In press.

[27] Judith L. Doyle SLK. Five beveled point geometry for a hypodermic needle. Becton Dickinson and Co 1998.

[28] Kim H, Colton JS. Fabrication and analysis of plastic hypodermic needles. J Med Eng Technol. 2005;29:181-6.

[29] Grujicic M, Zhao H. Optimization of 316 stainless steel/alumina functionally graded material for reduction of damage induced by thermal residual stresses. Materials Science and Engineering: A. 1998;252:117-32.

[30] Rotshtein VP, Ivanov YF, Markov AB, Proskurovsky DI, Karlik KV, Oskomov $\mathrm{KV}$, et al. Surface alloying of stainless steel 316 with copper using pulsed electron-beam melting of film-substrate system. Surface and Coatings Technology. 2006;200:6378-83.

[31] Cua Anastasia B, Wilhelm KP, Maibach HI. Frictional properties of human skin: relation to age, sex and anatomical region, stratum corneum hydration and transepidermal water loss. British Journal of Dermatology. 2006;123:473-9. 